\title{
The Relationship between Self-Esteem, Sense of Mastery and Humor as Personal Resources and Crisis-Coping Strategies in Three Generations
}

\author{
Pnina Ron, Michal Rovner \\ School of Social Work, University of Haifa, Mount Carmel, Haifa, Israel \\ Email: pitzyron@research.haifa.ac.il
}

Received 16 March 2014; revised 8 May 2014; accepted 21 May 2014

Copyright (C) 2014 by authors and Scientific Research Publishing Inc.

This work is licensed under the Creative Commons Attribution International License (CC BY).

http://creativecommons.org/licenses/by/4.0/

(c) (i) Open Access

\begin{abstract}
Aim: The study's aim is to examine the coping strategies from a perspective of intergenerational transmission. Methods: A self-report questionnaire was completed by 504 students, their parents, and their grandparents. Tools on the questionnaire assessed crisis perception as well as levels of sense of humor, sense of mastery, and self-esteem, as independent variables, and crisis-coping strategies, as the dependent variable. Results: Findings indicated that there was intergenerational transmission of the problem-focused coping strategy in general, and of the intra-personal resources of self-esteem, and sense of mastery, in particular. The major theoretical contribution of the study is in extending the concept of intergenerational transmission to include an additional realm; findings also substantiated and reinforced previous knowledge regarding the strategies for coping with stress and crises among various age groups. Conclusions: In terms of applicability, recognizing the phenomenon of intergenerational transmission provides a clinical tool that increases the possibility of coping with complex problems. In addition, it suggests the need to increase clients' awareness of the significant effects of intergenerational transmission.
\end{abstract}

\section{Keywords}

Intergenerational Transmission, Intra-Personal Resources, Crises-Coping-Strategies

\section{Introduction}

A crisis is defined as an imbalance between the severity of a problem, in terms of the importance attributed to it, and the resources available to the individual for coping with the problem. A crisis occurs when the person under 
stress reaches a turning point, which in effect constitutes a problem that cannot be solved using familiar coping strategies [1].

Each individual has a different style of coping in situations of crisis and stress. Some respond by taking action, some choose physical activities, while others might seek the help of friends and family in order to strengthen their sense of confidence, and yet others opt for avoidance. Each style is legitimate and serves the individual that uses it.

Coping is defined as an ongoing effort to attain cognitive and behavioral change, in an attempt to deal with specific demands, external and internal, which are considered burden some more beyond the resources available to the individual [2] [3].

The theoretical basis for the current study is the stress theory of Lazarus and Folkman [2], however, this study will examine perceptions of crisis rather than perceptions of stressful situations. This alteration is based on the assumption that a crisis develops following unsuccessful coping with a stressful situation. This theory presents two central processes that occur when a stressful situation is encountered: cognitive assessment and coping. In the process of cognitive assessment, first there is an initial assessment, which involves a judgment about the nature of the event-whether it is relevant, challenging, or stressful. If the event is perceived as stressful, a secondary assessment takes place, in which the individual assesses how to cope with events in order to solve the problem or reduce potential damage, and also considers which strategy would be the most effective for coping with the situation. Next is a stage of coping, which is derived from the first and second stages of cognitive assessment and takes into account the individual's typical style of coping with stress [2]. The researchers categorized the ways for coping with stress into two major types: problem-focused coping and emotion-focused coping styles. Problem-focused coping aims to solve the problem and change the external reality, in an attempt to influence the source of stress and thus reduce the tension. This type of strategy is used when one estimates that one is capable of coping with the source of the stress [3] [4]. The emotion-focused coping aims to channel feelings of stress and to redefine the problem in order to relieve the emotional tension. This type of coping does not attempt to cope with the stressful situation, but rather aims to reduce or manage the emotional distress that accompanies it. Problem-focused coping is associated with active strategies, whereas emotion-focused coping is associated with passive strategies [5].

An additional and major aspect of the theory relates to the external and internal resources available to the individual for the purpose of coping [6]. The individual's mental well-being can be affected not only by the coping strategies, but also by the various resources that are available for use [7] [8]. The current study focuses on the internal resources of self-esteem, sense of control, and humor, as well as on personal variables, particularly intergenerational transmission, and examines the relationship between these and strategies for coping with crisis situations.

Rosenberg [9] defines self-esteem as a positive or negative attitude of the individual towards the self. The term self-esteem includes an array of values and self-judgments regarding one's own thoughts, emotions, behaviors, abilities, and merits as a human being [10].

High levels of self-esteem have been associated in many studies with better mental health in general, better outcomes of coping, and lower percentages of depression [11]. Self-esteem is a resource for coping with situations of stress and crisis. It is been shown that high levels of self-esteem predict fewer stressful events over time [12] [13]. In addition, an association was found between self-esteem and problem-focused coping, between lack of self-esteem and emotion-focused coping [14]-[16], and between self-esteem and less use of avoidance strategies [14].

An individual's subjective feeling that significant events in life can be controlled is defined in the research literature as a sense of mastery [17] [18]. The individual has an ongoing feeling of being capable of influencing the environment in a manner that corresponds to one's needs. This is, in essence, an active belief that one can choose between responses of varying degrees of efficacy in order to attain a certain desired objective.

Various studies have found that there is a relationship between sense of mastery and coping strategies. A sense of mastery that derives from the perception that events can be controlled or changed creates positive feelings; this leads people to plan the actions they might take in stressful situations, which in turn strengthens their problem-focused coping strategies [19] [20]. In contrast, in situations in which a sense of mastery is low, coping strategies such as cognitive structuring, relaxation, and even avoidance could be more effective than others [2] [21].

It was also found that locus of control functions as a mediating variable that affects the way in which the indi- 
vidual assesses situations of stress and crisis [22]. The more the individual's locus of control is internal, the more likely is one to attribute to oneself the ability affect the events of one's life and the environment; as a result, less stress and anxiety are felt during crisis situations and the individual typically shows greater initiative for coping with problems encountered and tends to prefer problem-focused coping strategies to emotion-focused coping strategies [23] [24].

Humor is a complex phenomenon which involves a network of cognitive, behavioral, psychological, social, and emotional aspects [25]. In recent years, several studies have examined the use of humor as a resource for coping with stress and crisis. The study by Talbot and Lumden [26] found that individuals who used humor had a greater sense of self-efficacy and a stronger belief in their own abilities. In effect, humor provides a cognitive assessment of the situation and attenuates the individual's perception of the situation as a crisis, creating a greater sense of having control of the situation.

Individuals with a humoristic approach to life cope more effectively with stress and crisis, by distancing themselves from stressful situations and increasing their sense of control when coping with stress [27]. In stressful situations, humor serves the function of disconnecting, which is used for adapting and protecting oneself in difficult life situations [28]. Nevertheless, the study conducted by Celso, Ebner, \& Burkhead [29] found that the use of humor did not significantly improve the negative effect of stressful and crisis events, but only relieved the tension in these situations.

Intergenerational transmission means copying psychological characteristics from one generation to the next: it is the process through which one generation has a psychological effect on the attitudes and approaches of the following generation [30]. Several theoretical approaches examine intergenerational transmission, for example, the behavioral, familial, and psychoanalytic theories, which differ in terms of their understanding of the process that takes place. The behavioral theories emphasize processes of imitation and empowerment as a major type of learning. Children learn not only through experience, but also by observing the behaviors of central figures in their lives [31] [32].

The theory of social learning, which is part of the behavioral approach, is used in several research studies as a basis for studying intergenerational transmission of behaviors. Hence, this study too focuses on the theory of social learning. According to the social learning theory, children's behavior is formed by imitating behaviors that they noticed were valued by others [33] [34]. Researchers have noted the effects of intergenerational transmission in studies that focused on loneliness [35] on parenting patterns [30], and on violent and dangerous behaviors, such as smoking, and alcohol or drug abuse [34]. Furthermore, the intergenerational transmission effect was found in studies that investigated second-generation descendants of Holocaust survivors. It was found that aspects of mastery, depressive moods, and anxiety are transmitted from one generation to the next [36].

The possibility that intergenerational transmission affects the way individuals cope with stress and crisis has received only limited attention; however, relying on the consistent findings obtained over time by numerous studies of generational transmission, it is possible to draw assumptions pertinent to the current study, as follows. The similarities found between mothers and daughters are generally greater than the similarities found between fathers and sons, and there is a gender effect which manifests as a greater similarity between mothers and daughters than between mothers and sons [37] [38].

Based on information presented herein, the current study attempted to examine the effect of intergenerational transmission on participants' perceptions of coping with crises, while taking into account internal resources.

The main research hypothesis was that a positive relationship would be found between internal resources and problem-focused coping strategies, and a negative relationship would be found between internal resources and emotion-focused coping strategies, among members of three consecutive generations.

\section{Methods}

\subsection{Population and Sample}

The study population included residents from the northern part of the state of Israel, families in which there were three generations, and a member of the youngest generation was enrolled in an undergraduate program in social work at Haifa University. From a group of 450 students, the selected sample included those whose families consisted of three consecutive generations. A convenience sample was used. After examining the triadic sets of questionnaires that were completed, 168 triadic sets remained, each representing a family of three generations. 
Due to the fact that the sample came from the school of social work and that students were asked to invite family members of other generations who matched their own gender, the number of women in the entire sample was higher than that of men.

Table 1 describes the demographic characteristics of the participants.

According to the information in Table 1, it appears that the majority of participants were born in Israel (74.4\%), slightly more than half of the participants were either married or living with a partner (55.4\%), were Jewish (56.9\%), and secular (54.4\%). In addition, demographics indicated an inverse correlation between participants' age and the level of education (average education: 8.22 years).

\subsection{Research Tools}

The tool used in this research was a self-report questionnaire that included the following sections.

(a) A demographic questionnaire which examined participants' background variables.

(b) A questionnaire of crisis perception, which examined participants' subjective understanding of the crises that individuals in our society encounter. Questions relate to a personal crisis, a family crisis, a national crisis, and the taking of responsibility for each type of crisis. The questionnaire was composed for the purpose of the current study; hence, a pilot sample of 70 participants was used to determine its reliability. Results indicated a reliability of 0.58 Cronbach's alpha. Participants found it difficult to understand the concept of crisis, and therefore an explanatory paragraph was added to the questionnaire in order to clarify the meaning of crisis.

(c) A questionnaire on coping strategies: the self-report Cope Questionnaire of Carver and colleagues [2] was used to examine the way that individuals cope with stressful situations and negative events in daily life. The original questionnaire includes 15 different coping strategies, each of which consists of a four item subscale (for

Table 1. Background characteristics $(N=504)$.

\begin{tabular}{|c|c|c|c|}
\hline Generation & Variable & $\mathbf{N}$ & $\%$ \\
\hline $\begin{array}{l}\text { Grandparents } \\
\text { Parents } \\
\text { Grandchildren }\end{array}$ & Frequency & $\begin{array}{l}168 \\
168 \\
168\end{array}$ & $\begin{array}{l}33.3 \\
33.3 \\
33.3\end{array}$ \\
\hline All sample & $\begin{array}{l}\text { Gender } \\
\text { Male } \\
\text { Female }\end{array}$ & $\begin{array}{c}63 \\
441\end{array}$ & $\begin{array}{l}12.5 \\
87.5\end{array}$ \\
\hline All sample & $\begin{array}{l}\text { Country of Birth } \\
\text { Israel } \\
\text { Europe/America } \\
\text { North Africa/Asia }\end{array}$ & $\begin{array}{c}375 \\
90 \\
39\end{array}$ & $\begin{array}{c}74.4 \\
17.8 \\
7.8\end{array}$ \\
\hline All sample & $\begin{array}{c}\text { Nationality } \\
\text { Jew } \\
\text { Arab } \\
\text { Other }\end{array}$ & $\begin{array}{c}287 \\
207 \\
10\end{array}$ & $\begin{array}{c}56.9 \\
41.0 \\
2.1\end{array}$ \\
\hline All sample & $\begin{array}{c}\text { Family Status } \\
\text { Married/living with a spouse } \\
\text { Unmarried/live alone }\end{array}$ & $\begin{array}{l}279 \\
225\end{array}$ & $\begin{array}{l}55.4 \\
44.6\end{array}$ \\
\hline \multirow[t]{2}{*}{ All sample } & $\begin{array}{c}\text { Level of Religiosity } \\
\text { Orthodox } \\
\text { Conservative } \\
\text { Secular }\end{array}$ & $\begin{array}{l}102 \\
123 \\
273\end{array}$ & $\begin{array}{l}20.2 \\
24.4 \\
54.4\end{array}$ \\
\hline & & $\mathbf{M}$ & SD \\
\hline $\begin{array}{l}\text { Grandparents } \\
\text { Parents } \\
\text { Grandchildren }\end{array}$ & Age & $\begin{array}{l}76.48 \\
49.86 \\
23.29\end{array}$ & $\begin{array}{l}6.71 \\
5.78 \\
3.45\end{array}$ \\
\hline $\begin{array}{l}\text { Grandparents } \\
\text { Parents } \\
\text { Grandchildren }\end{array}$ & Years of Education & $\begin{array}{c}8.22 \\
13.13 \\
14.55\end{array}$ & $\begin{array}{c}5.05 \\
4.4 \\
2.39\end{array}$ \\
\hline $\begin{array}{l}\text { Grandparents } \\
\text { Parents } \\
\text { Grandchildren }\end{array}$ & Number of Children & $\begin{array}{l}4.72 \\
3.47 \\
1.25\end{array}$ & $\begin{array}{c}3.27 \\
1.39 \\
0.5\end{array}$ \\
\hline
\end{tabular}


a total of 60 items), and each item describes a particular coping strategy in a single sentence. Responses are provided using a Likert-like scale ranging from 1 to 4 .

The current study used a shorter version of this questionnaire which was translated into Hebrew by Zeidner and Ben-Zur [39]. The questionnaire includes 30 items pertaining to 15 different coping strategies, such as active coping, positive outlook and growth, planning, and emotional support, to mention a few. These strategies are categorized into two groups: problem-focused coping strategies and emotion-focused coping strategies. A high score on the questionnaire indicates a greater use of the coping strategies examined by the questionnaire. The range of internal consistency was between 0.62 and 0.92 Cronbach's alpha and in the current study between 0.69 and 0.90 Cronbach's alpha.

(d) To examine the variable of humor, this study used a self-report questionnaire by Thorson and Powell [40]. The multidimensional sense of humor scale (MSHS) was constructed in order to assess humor. It contains 24 items that relate to four different dimensions of humor: humor generation, use of humor as a coping mechanism, appreciation of humor, and attitudes towards humor and humorous persons. Items were rated on a Likert-like scale from 1 to 5 ( 1 = disagree completely; 5 = agree completely). The reliability of the tool was 0.92 Cronbach's alpha in [40] and 0.91 Cronbach's alpha in the current study.

(e) To examine self-esteem, the self-report questionnaire of Rosenberg was used [9]. The questionnaire consists of ten items, ranked on a Likert-like scale ranging from $1=$ disagree completely, to $5=$ agree completely. Five of the items relate to positive feelings regarding self-esteem, such as "I feel I have several good qualities", and five items relate to negative feelings regarding self-esteem, such as "in general, I tend to consider myself a failure". The overall ranking is calculated according to the item averages, such that a high ranking corresponds to a high level of self-esteem. The questionnaire was translated into Hebrew by Hobfoll and Walfisch [41], who reported reliability rates between 0.81 Cronbach's alpha and 0.90 Cronbach's alpha. In the current study, the entire tool reliability was 0.84 .

(f) To examine the variable of sense of mastery, the self-report questionnaire of Pearlin and Schooler [18] was used. This questionnaire was translated into Hebrew by Hobfoll and Walfisch [41]. It consists of seven items ranked on a Likert-like scale ranging from 1 to 5 , whereby 1 = disagree completely, and 5 = agree completely. The average score for these seven items represents the individual's score, after inverting the values so that a high score indicated a high sense of mastery. According to Ben-Zur [19], the questionnaire's reliability was 0.80 Cronbach's alpha.

Data was collected and the SPSS statistics procedures have been conducted in the current study.

The study was approved by the ethical committee of the University of Haifa, Israel.

\section{Results}

In examining the findings and their relation to the study hypothesis, the first step was to examine the connections between the interpersonal variables pertaining to the entire sample. A strong and significant positive connection was found between the variable of sense of mastery and the variable of self-esteem $(r=0.54, p<0.01)$, and between the variable of sense of mastery and the variable of humor $(r=0.43, p<0.01)$. A strong and significant negative connection was found between the variable of sense of mastery and the perception of crisis $(r=$ $0.47, p<0.01$ ), and a significant and negative connection of medium strength was found between the variable of self-esteem and the perception of crisis $(r=-0.24, p<0.01)$. To determine whether there was a connection between the intrapersonal variables (sense of mastery, self-esteem, and humor) and the two strategies for coping with crisis (problem-focused coping strategy and emotion-focused coping strategy) among the three generations, Spearman's correlation tests were conducted. The findings are presented in Table 2.

According to the information in Table 2, it appears that among the generation of grandchildren, there was a positive connection between the variable of self-esteem and the use of the problem-focused coping strategy ( $p<$ 0.01 ) and a negative connection between self-esteem and the use of the emotion-focused coping strategy ( $p<$ $0.05)$. In addition, it was found that the variable of sense of mastery was positively connected with the problemfocused coping strategy $(p<0.01)$ and negatively connected with the emotion-focused coping strategy $(p<$ 0.05). No significant connection was found between humor and the two types of strategies among the generation of grandchildren.

Findings with similar tendencies were found among participants of the parent and grandparent generations. In addition, these two generations were similar to that of the grandchildren in that no significant connection was 
Table 2. Spearman correlations between personal resources strategies for coping with crisis in three Israeli generations.

\begin{tabular}{ccccccc}
\hline \multicolumn{2}{c}{ Generation } & \multicolumn{2}{c}{ Grandparents } & \multicolumn{2}{c}{ Parents } & \multicolumn{2}{c}{ Grandchildren } \\
Resource & Strategy Problem-focused & Emotion-focused & Problem-focused \\
strategy & strategy & strategy & $\begin{array}{c}\text { Emotion-focused } \\
\text { strategy }\end{array}$ & $\begin{array}{c}\text { Problem-focused } \\
\text { strategy }\end{array}$ & $\begin{array}{c}\text { Emotion-focused } \\
\text { strategy }\end{array}$ \\
\hline Self-esteem & $0.39^{*}$ & $-0.2^{*}$ & $0.47^{* *}$ & $-0.35^{* *}$ & $0.49^{* *}$ & $-0.1^{*}$ \\
Sense of Mastery & $0.38^{*}$ & $-0.29^{*}$ & $0.41^{* *}$ & $-0.53^{* *}$ & $0.42^{* *}$ & $-0.3^{*}$ \\
Humor & 0.14 & -0.14 & 0.26 & -0.24 & 0.12 & -0.1 \\
\hline
\end{tabular}

${ }^{*} P<0.05 ;{ }^{* *} p<0.01$.

found between humor and the two types of strategies for coping with crisis.

To examine the differences between the two coping strategies in terms of crisis perception and internal resources among all participants in all three generations, a two way MANOVA test was conducted. For the purpose of statistical analysis, each interpersonal variable was assigned to one of two groups, based on scores: one group had above-average scores (high group), while the other had below-average scores (low group).

The generational variable had a significant effect on the average score for problem-focused coping strategy $[F(5,160)=5.36, p<0.01]$. To examine the source of these differences, a continuous Scheffe test was conducted, which revealed that the average score for problem-focused coping strategy among the generation of grandparents was significantly lower than that found in the generation of either the parents or the grandchildren.

Findings of the variance tests indicated a significant effect of the variable of a self-esteem on the average score for problem-focused coping strategy $[F(5,160)=12.9, p<0.01]$, such that participants with a high score on self-esteem were more likely to use the problem-focused coping strategy than were participants whose average score on self-esteem was low.

To examine the quality of the interaction between the variable of the generation and the variable of sense of mastery and their effects on problem-focused coping strategy, simple effect analyses were conducted using a one-way ANOVA. The variable of the generation was found to have a significant and simple effect on the use of problem-focused coping strategy among participants with a high average score on the variable of sense of mastery $[F(20,65)=1.90, p<0.05]$.

Additional findings are presented in Table 3 and Table 4.

Based on these two tables and the remaining findings, it appears that differences found between the three generations on the three variables of intrapersonal resources were related to the problem-focused strategy for coping with crises. Participants who reported high levels of self-esteem and sense of mastery tended to use the problem-focused strategy when coping with crisis, while those who reported low levels of self-esteem tended to use the emotion-focused coping strategy. Very similar findings were obtained regarding the variable of sense of mastery.

Regarding these two variables, it was found that there appeared to be intergenerational transmission, from the grandparents to the parents and from the parents to the grandchildren, of these intrapersonal resources, which affect the use of the problem-focused coping strategy.

Contrary to the hypothesis, no significant effect was found for the effect of the variable of humor on either of the two coping strategies.

For an overview of the findings, a stepwise regression analysis was conducted, to help determine which variables best explained the choice of problem-focused coping strategy for each of the generations. Some demographic variables were also included in this analysis (gender, family status, education level, and level of religiosity). Findings indicated that the model was significant for the three generations. Among the grandparent generation $[F(3,27)=15.67, p<0.01]$, the sense of mastery variable explained $31 \%$ of the use of the problem-focused strategy $(\beta=0.49, p<0.01)$. The remaining variables did not impact the model.

Among the parent generation $[F(6,17)=19.09, p<0.01]$, the variable of self-esteem and the variable of sense of mastery explained $34 \%$ of the use of the problem-focused coping strategy. The strongest predictor of the use of the strategy was the variable of sense of mastery $(\beta=0.50, p<0.01)$. The next best predictor was the variable of self-esteem ( $\beta=0.39, p<0.05$ ). The remaining variables did not impact the model.

Also among the generation of grandchildren, the model was found to be significant $[F(9,12)=12.22, p<$ 0.01], whereby the variable of self-esteem and the variable of sense of mastery explained $36 \%$ of the use of the problem-focused coping strategy. The relatively highest predictor of the use of this strategy was the variable of 
Table 3. Means, standard deviation, and F tests of the problem-focus strategy with the crisis perception according the internal resources and the generation.

\begin{tabular}{|c|c|c|c|c|}
\hline Generation & Variable & $\mathbf{M}$ & SD & $F$ \\
\hline \multicolumn{5}{|c|}{ Self Esteem } \\
\hline Grandparents & $\begin{array}{l}\text { Low } \\
\text { High }\end{array}$ & $\begin{array}{l}3.10 \\
3.13\end{array}$ & $\begin{array}{l}0.47 \\
0.49\end{array}$ & \multirow[b]{3}{*}[F(5,160)=12.9,p<0.01]{} \\
\hline Parents & $\begin{array}{l}\text { Low } \\
\text { High }\end{array}$ & $\begin{array}{l}3.11 \\
3.42\end{array}$ & $\begin{array}{l}0.46 \\
0.32\end{array}$ & \\
\hline \multirow[t]{2}{*}{ Grandchildren } & $\begin{array}{l}\text { Low } \\
\text { High }\end{array}$ & $\begin{array}{l}3.20 \\
3.54\end{array}$ & $\begin{array}{l}0.40 \\
0.29\end{array}$ & \\
\hline & \multicolumn{3}{|c|}{ Sense of Mastery } & \\
\hline Grandparents & $\begin{array}{l}\text { Low } \\
\text { High }\end{array}$ & $\begin{array}{l}3.13 \\
3.09\end{array}$ & $\begin{array}{l}0.47 \\
0.51\end{array}$ & \\
\hline Parents & $\begin{array}{l}\text { Low } \\
\text { High }\end{array}$ & $\begin{array}{l}3.13 \\
3.38\end{array}$ & $\begin{array}{l}0.49 \\
0.30\end{array}$ & \multirow[b]{2}{*}[F(5,160)=10.07,p<0.01]{} \\
\hline \multirow[t]{2}{*}{ Grandchildren } & $\begin{array}{l}\text { Low } \\
\text { High }\end{array}$ & $\begin{array}{l}3.10 \\
3.52\end{array}$ & $\begin{array}{l}0.40 \\
0.29\end{array}$ & \\
\hline & Humor & & & \\
\hline Grandparents & $\begin{array}{l}\text { Low } \\
\text { High }\end{array}$ & $\begin{array}{l}3.11 \\
3.12\end{array}$ & $\begin{array}{l}0.41 \\
0.57\end{array}$ & \multirow{3}{*}[F(5,160)=1.47,\mathrm{n}.\mathrm{s}.]{} \\
\hline Parents & $\begin{array}{l}\text { Low } \\
\text { High }\end{array}$ & $\begin{array}{l}3.16 \\
3.33\end{array}$ & $\begin{array}{l}0.42 \\
0.42\end{array}$ & \\
\hline Grandchildren & $\begin{array}{l}\text { Low } \\
\text { High }\end{array}$ & $\begin{array}{l}3.33 \\
3.41\end{array}$ & $\begin{array}{l}0.48 \\
0.34\end{array}$ & \\
\hline
\end{tabular}

Table 4. Means and standard deviation and F tests of the emotion-focused strategy with the crisis perception according to the internal resources and the generation.

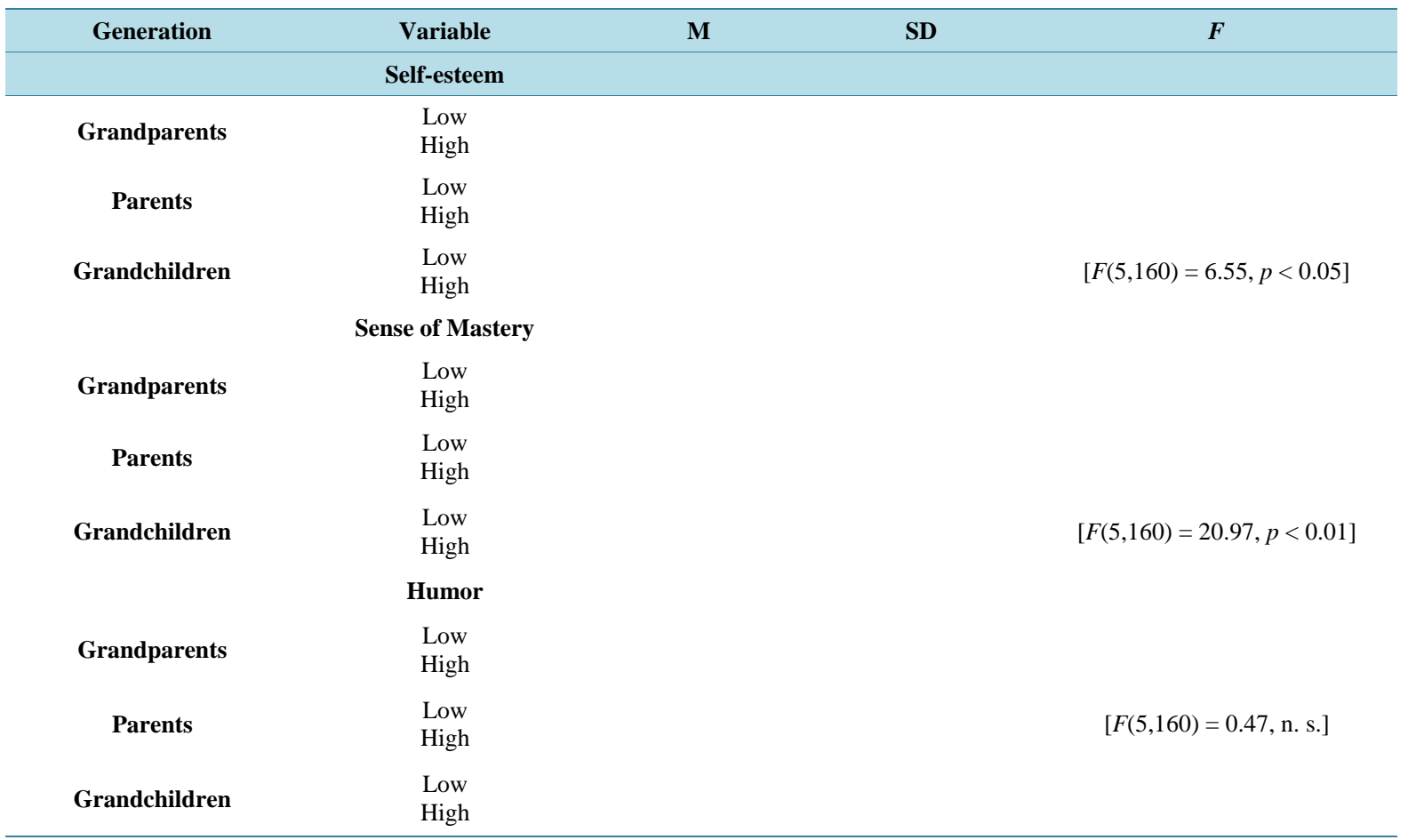

self-esteem $(\beta=0.38, p<0.01)$, followed by the variable of sense of mastery $(\beta=0.33, \mathrm{p}<0.01)$. The remaining variables did not impact the model. 


\section{Discussion}

Many studies have discussed the strategies for coping with stress and crisis in various life events, the importance of understanding which strategy one activates, and the factors that affect the choice of strategy. However, very little research has been done on the topic from the point of view of intergenerational transmission and its effect on coping strategies and crisis perception.

In general, findings of the current study suggest that there is intergenerational transmission of the problemfocused coping strategy and crisis perception between grandparents and parents and between parents and grandchildren, particularly as this relates to three intrapersonal coping resources: self-esteem, sense of mastery, and humor. This finding is consistent with those of other studies in the professional literature that identified the existence of intergenerational transmission, as found for example in regard to attachment [42], on the subject of second-generation to Holocaust survivors [43], and risk behaviors [44]. Very few studies have focused on similar issues, such as anxiety, depression and trauma. To the best of the author's knowledge, no study has examined intergenerational transmission in the context of either the perception of crisis or strategies for coping with crisis.

The finding of intergenerational transmission can be explained by referring to Bowen's theory of family systems [45]. This theory provides a comprehensive conceptualization of people and interpersonal relationships from a generational perspective [46]. According to Bowen, the family is a single unit consisting of a network of relationships that are intertwined and controlled by the innate impulses of all of its members. These innate impulses have a strong effect on the thoughts, emotions, and behaviors of each and every member of the family. None of the family members is completely autonomous psychologically; rather, all of the members are greatly influenced by the familial relationship [47].

Over several decades, quite a bit of attention has been dedicated in the professional literature to the positioning and role of grandparents in the multigenerational family. Grandparents were not considered an integral part of the family, just as the birth of a grandchild was not considered a significant event in the life of the elderly person. It is important to remember that the expeditious modernization processes that have occurred in the Western family have included also a change in the role structuring within the family, whereby the family, which was previously characterized in terms of its members' social roles, is now defined in terms of its members' social relationships. This has two major implications. The first is related to the demographic level: on the one hand there has been an increase in longevity (the family contains up to four or five generations), while on the other hand, there has been a significant decrease in fertility and birth rates. The manifestation of this shift is in the classical family structure (i.e., mother father, and children), as more and more families consist of a single parent, singlesex parents, or multiple parents, to name a few developments. Concurrent with these demographic and structural changes, there has been also a shift in the attitude towards the generation of the grandparents. There is a growing tendency to recognize the importance of multigenerational relationships within the family. A study conducted by Kornhaber [48] examined the reciprocal effects among the generations in a multigenerational family. Findings demonstrated that the relationship between grandparent and grandchild was ranked as second in importance (ahead of sibling relationships). Carter and McGoldrick [49] discussed the lifecycle of the individual in relation to both the nuclear family and the multigenerational family: they described a dynamic web of relationships, which has an effect on, and is affected byall of its members, in ways that are much more penetrating than mere ethnicity, religion, and habits. Rather, this web of reciprocal relationships affects perceptions, attitudes, values, and moral codes. According to the authors of said study, this is, in fact, the essence of intergenerational transference.

Another way to comprehend the findings of the current study is through an analogy with intergenerational transference of trauma. In this type of transference, mental distress is experienced through one's long-term relationship with an individual who had been directly affected by a traumatic event [50] [51]. In other words, even indirect exposure to an event can lead to changes in the person who is close to the injured party. The person who is closely related to the injured party develops symptoms of trauma as a result of exposure to the manifestations of trauma demonstrated by the injured party. Given the emotional involvement between the two individuals, the relative's reaction to this exposure is secondary traumatization. In intergenerational transmission, any experiences, crises, or traumas that have remained unprocessed in the parent generation are transmitted to the children in an uncontrolled and subconscious manner [52] [53]. When intergenerational transmission occurs, the child functions as a receptacle for the parents anxieties and pain; however, despite the fact that the term relates to the transmission of experiences from negative life events, it may be assumed that the mechanism can work also in the transmission of positive experiences and coping methods. The parent's manners and strategies for 
coping are transmitted to the child, as are the parent's perceptions and worldview. In cases where trauma was transmitted from one generation to the next, it is possible that similar coping strategies would have developed in each of the generations [51] [54].

An additional interesting finding that emerged from the current study was the absence of a significant correlation between the generational factor and the average scores for the emotion-focused coping strategy in relation to the three personal resources, in any of the three generations. As previously noted by Lazarus and Folkman [5], problem-focused coping is more frequently used in situations of distress in which the individual considers the stressful event to be under one's control, whereas emotion-focused coping is more frequently found in situations in which the individual feels that the source of stress is not within one's control. An efficient coping strategy consists in exerting effort to reduce the physiological and psychological distress and preserve one's social functioning [55]. According to the professional literature, it appears that problem-focused coping is a more efficient strategy: it reduces negative emotional reactions and improves one's ability to cope with and one's perception of the event [19] [56].

In stressful situations and in crises, coping is likely to be affected by the various resources that the individual uses [24]. The theory of resilience claims that people have strengths and resources, which they use for selfprotection and which assist them in coping with various situations [57] [58]. The current study focused on the personal resources of self-esteem, sense of mastery, and humor, which have been recognized in the professional literature as significant factors when coping with situations of stress and crisis. Findings of the study indicated a positive correlation between the level of self-esteem and the problem-focused coping strategy in the generations of the parents and of the grandchildren, whereas a negative correlation was found in these generations between self-esteem and the emotion focused coping strategy. These findings substantiate those of Thoits' study [16], which found a positive correlation between self-esteem and the problem-focused coping strategy in a context that required coping with crisis. Additional studies have shown that the resource of self-esteem acts as a mediating factor between the selected coping strategy and the effects of the stressful event or crisis. It is possible that self-esteem inhibits any further development of the stress factor, by affecting the selection of strategies used for coping [59] [60].

The current study also found a positive correlation between sense of mastery and the problem-focused coping strategy among the three generations. It appears that the very belief that we are able to control various events in our lives, particularly those which we view as negative, reduces the effects of these events, even if we take no actual steps to control them [19]. These findings coincide with those of other studies, which found that sense of mastery is related to the problem-focused coping strategy [24] [61].

The study had several limitations, among them the sampling method, which obviously has implications for the generalizability of the findings. The study was based on a sample of students who were asked to select one parent and one grandparent, and to provide their responses without relating to the other parent or any of the other grandparents. On the one hand, it may seem that these findings are unusual given the clearly subjective manner of participant recruitment; however, it is also possible that selecting one parent and not the other indicates an a priori ideological affinity or similar perceptions related to coping with crisis. An additional limitation is related to the manner in which intergenerational transmission was measured. In the current study, statistical analyses were used, rather than the specific tool for examining intergenerational transmission.

Finally, the current study relied on self-reporting tools that were not devoid of biases related to peer pressure and reporting precision. The collected data could have been affected by people's natural inclination to present themselves in a positive light. Moreover, answers provided when completing the questionnaire in an unprotected environment may not reflect real-time behaviors. Hence, additional research on this topic is recommended.

\section{Conclusion}

The results of the current study have significant implications for both the theoretical and practical views. The study's contribution to the theoretical dimension is the development of the term "intergenerational transmission" to other areas on one hand. On the other hand, this study establishes and strengthens the existing knowledge on coping with stress and crisis. In the practical dimension, recognizing the phenomenon of intergenerational transmission provides an important tool for healing as a part of treatment and extends the possibility to deal with complex problems. In addition, it emphasizes the need to expand the awareness of the therapists about the importance and influence of the intergenerational transmission. 


\section{References}

[1] Carver, C.S., Scheier, M. and Weintraub, J.K. (1989) Assessing Coping Strategies: A Theoretically Based Approach. Journal of Personality and Social Psychology, 56, 267-283. http://dx.doi.org/10.1037/0022-3514.56.2.267

[2] Lazarus, R.S. and Folkman, S. (1984) Stress, Appraisal, and Coping. Springer, New York.

[3] Lazarus, R.S. (1980) Thoughts on the Relations between Cognition and Emotion. American Psychologist, 37, 10191024. http://dx.doi.org/10.1037/0003-066X.37.9.1019

[4] Folkman, S. and Lazarus, R.S. (1980) An Analysis of Coping in a Middle-Aged Community Sample. Journal of Health and Social Behavior, 21, 219-239. http://dx.doi.org/10.2307/2136617

[5] Ben-Zur, H. (2002) Monitoring/Blunting and Social Support: Association with Coping and Affect. International Journal of Stress Management, 9, 357-377.

[6] Coyne, J.C. and Downey, G. (1991) Social Factors and Psychopathology. Annual Review of Psychology, 42, 401-425. http://dx.doi.org/10.1146/annurev.ps.42.020191.002153

[7] Fondacaro, M.R. and Moos, R.H. (1987) Social Support and Coping: A Longitudinal Analysis. American Journal of Community Psychology, 15, 653-673. http://dx.doi.org/10.1007/BF00929917

[8] Moos, R.H. and Schaefer, J.A. (1993) Coping Resources and Processes: Current Concepts and Measures. In: Goldberger, L. and Breznitz, S., Eds., Handbook of Stress: Theoretical and Clinical Aspects, 2nd Edition, The Free Press, New York, 234-257.

[9] Rosenberg, M. (1965) Society and the Adolescent Self Image. Princeton University Press, Princeton.

[10] Coopersmith, S. (1967) The Antecedents of Self-Esteem. Freeman, San Francisco.

[11] Birndorf, S., Ryan, S., Auinger, P. and Aten, M. (2005) High Self-Esteem among Adolescents: Longitudinal Trends, Sex Differences, and Protective Factors. Journal of Adolescent Health, 37, 194-201. http://dx.doi.org/10.1016/j.jadohealth.2004.08.012

[12] Thoits, P.A. (1994) Stressors and Problem Solving: The Individual as Psychological Activist. Journal of Health and Social Behavior, 35, 143-159. http://dx.doi.org/10.2307/2137362

[13] Turner, H.A. and Turner, R.J. (2005) Under-Standing Variations in Exposure to Social Stress. Health, 9, $209-240$.

[14] Aspinwall, L.G. and Taylor, S.E. (1992) Modeling Cognitive Adaptation: A Longitudinal Investigation of the Impact of Individual Differences and Coping on College Adjustment and Performance. Journal of Personality and Social Psychology, 63, 989-1003. http://dx.doi.org/10.1037/0022-3514.63.6.989

[15] Terry, D.J. (1991) Coping Resources and Situational Appraisals as Predictors of Coping. Journal of Personality and Individual Differences, 12, 1031-1047. http://dx.doi.org/10.1016/0191-8869(91)90033-8

[16] Thoits, P.A. (1999) Self, Identity, Stress, and Mental Health. In: Aneshensel, C.S. and Phelan, J.C., Eds., Handbook of the Sociology of Mental Health, Kluwer Academic-Plenum, New York, 345-368.

[17] Michinov, N. (2005) Social Comparison, Perceived Control and Occupational Burnout. Applied Psychology, 54, 99118. http://dx.doi.org/10.1111/j.1464-0597.2005.00198.x

[18] Pearlin, L.I. and Schooler, C. (1978) The Structure of Coping. Journal of Health \& Social Behavior, 19, 2-21. http://dx.doi.org/10.2307/2136319

[19] Ben-Zur, H. (2002) Monitoring/Blunting and Social Support: Associations with Coping and Affect. International Journal of Stress Management, 9, 357-377. http://dx.doi.org/10.1023/A:1019990518144

[20] Cicirelli, V.G. (1992) Siblings as Caregivers in Middle and Old Age. In: Dwyer, J.W. and Coward, R.T., Eds., Gender, Families, and Elder Care, Sage, Newbury Park, 84-101.

[21] Begley, T.M. (1998) Coping Strategies as Predictors of Employee Distress and Turnover after an Organizational Consolidation: A Longitudinal Analysis. Journal of Occupational and Organizational Psychology, 71, 305-329. http://dx.doi.org/10.1111/j.2044-8325.1998.tb00679.x

[22] Hagger, M.S. and Orbell, S. (2003) A Meta-Analytic Review of the Common-Sense Model of Illness Representations. Psychology and Health, 18, 141-184. http://dx.doi.org/10.1080/088704403100081321

[23] Anderson, C.R. (1977) Locus of Control, Coping, Behaviors and Performance in a Stress Setting: A Longitudinal Study. Journal of Applied Psychology, 62, 446-451. http://dx.doi.org/10.1037/0021-9010.62.4.446

[24] Lazarus, R.S. (1966) Psychological Stress and the Coping Process. McGraw-Hill, New York.

[25] Betha, L.S. (2001) The Function of Humor within the Lives of Older Adults. Communication Quarterly, 49, 49-56.

[26] Talbot, L.A. and Lumden, D.B. (2000) On the Association between Humor and Burnout. Humor: International Journal of Humor Research, 13, 419-428. http://dx.doi.org/10.1515/humr.2000.13.4.419

[27] Martin, R.A. (2004) Sense of Humor and Physical Health: Theoretical Issues, Recent Findings, and Future Directions. 
Humor, 17, 1-19. http://dx.doi.org/10.1515/humr.2004.005

[28] Berk, R. (2001) The Active Ingredients in Humor: Psycho Physiological Benefits and Risks for Older Adults. Educational Gerontology, 27, 323-339. http://dx.doi.org/10.1080/036012701750195021

[29] Celso, B.G., Ebener, D.J. and Burkhead, E.J. (2003) Humor Coping, Health Status, and Life Satisfaction among Older Adults in Assisted Living Facilities. Aging \& Mental Health, 7, 438-445. http://dx.doi.org/10.1080/13607860310001594691

[30] Ijzendoorn, M.H. (1992) Intergenerational Transmission of Parenting: A Review of Studies in Nonclinical Populations. Developmental Review, 12, 76-99. http://dx.doi.org/10.1016/0273-2297(92)90004-L

[31] Bandura, A. (1971) Psychological Modeling: Conflicting Theories. Aldine-Atherton, Chicago.

[32] McEwen, K.E. (1994) Refining the Intergenerational Transmission Hypothesis. Journal of Interpersonal Violence, 9, 350-365. http://dx.doi.org/10.1177/088626094009003005

[33] Bandura, A. (1977) Social Learning Theory. Prentice Hall, Englewood Cliffs.

[34] Corvo, K. and Carpenter, E.H. (2000) Effects of Parental Substance Abuse on Current Levels of Domestic Violence: A Possible Elaboration of Intergenerational Transmission Processes. Journal of Family Violence, 15, 123-135. http://dx.doi.org/10.1023/A:1007557626788

[35] Lobdell, J. and Perlman, D. 1986) The Intergenerational Transmission of Loneliness: A Study of College Females and Their Parents. Journal of Marriage and the Family, 48, 589-595. http://dx.doi.org/10.2307/352045

[36] Almagor, M. and Leon, G.R. (1989) Transgenerational Effects of the Concentration Camp Experience. In: Marcus, P. and Rosenberg, A., Eds., Healing Their Wounds: Psychotherapy with Holocaust Survivors and Their Families, Praeger, New York, 183-195.

[37] Bandura, A., Ross, D. and Ross, S.A. (1963) Vicarious Reinforcement and Imitative Learning. Journal of Abnormal and Social Psychology, 67, 601-607. http://dx.doi.org/10.1037/h0045550

[38] Bartle, S.E. and Anderson, S.A. (1991) Similarity between Parents and Adolescents Levels of Individuation. Adolescence, 26, 913-924.

[39] Zeidner, M. and Ben-Zur, H. (1993) Coping with a National Crisis: The Israeli Experience with the Threat of Missile Attacks. Personality and Individual Differences, 14, 209-224. http://dx.doi.org/10.1016/0191-8869(93)90191-5

[40] Thorson, J.A. and Powell, F.C. (1993) Development and Validation of a Multidimensional Sense of Humor Scale. Journal of Clinical Psychology, 49, 13-23. http://dx.doi.org/10.1002/1097-4679(199301)49:1<13::AID-JCLP2270490103>3.0.CO;2-S

[41] Hobfoll, S.E. and Walfisch, S. (1984) Coping with a Threat to Life: A Longitudinal Study of Self-Concept, Social Support, and Psychological Distress. American Journal of Community Psychology, 12, 87-100. http://dx.doi.org/10.1007/BF00896930

[42] Wiseman, H., Metzl, E. and Barber, J.P. (2006) Anger, Guilt, and Intergenerational Communication of Trauma in the Interpersonal Narratives of Second Generation Holocaust Survivors. American Journal of Orthopsychiatry, 76, 176184. http://dx.doi.org/10.1037/0002-9432.76.2.176

[43] Kellermann, N. (2001) Transmission of Holocaust Trauma-An Integrative View. Israel Journal of Psychiatry, 64, 256-267.

[44] Bell, Y.R., Bierer, L.M. and Schmeidler, J. (2008) Maternal, Not Paternal, PTSD Is Related to Increased Risk for PTSD in Offspring of Holocaust Survivors. Journal of Psychiatric Research, 42, 1104-1111. http://dx.doi.org/10.1016/j.jpsychires.2008.01.002

[45] Bowen, M. (1978) Family Therapy in Clinical Practice. Jason Aaronson, New York.

[46] Nichols, M.P. and Schwartz, R.C. (1995) Family Therapy: Concepts and Methods. 4th Edition, Allyn \& Bacon, Boston.

[47] Kerr, M.M. and Bowen, M. (1988) Family Evaluation. Norton, New York.

[48] Kornhaber, A. (1997) Grandparenthood and the New Social Contract. Research and Aging, 1, 108-132.

[49] Carter, B. and McGoldrick, M. (2005) The Expended Family Life Cycle: Individual, Family and the Social Perspectives. Allyn and Bacon, Boston.

[50] Rosenheck, R. and Nathan, P. (1985) Secondary Traumatization in the Children of Vietnam Veterans with Post-Traumatic Stress Disorder. Hospital and Community Psychiatry, 36, 538-539.

[51] Lev-Wiesel, R. (2007) Intergenerational Transmission of Trauma across Three Generations: A Preliminary Study. Qualitative Social Work, 6, 75-94. http://dx.doi.org/10.1177/1473325007074167

[52] Aldwin, C.M., Sutton, K.J., Chiara, G. and Spiro, A. (1996) Age Differences in Stress, Coping, and Appraisal: Findings from the Normative Aging Study. Journal of Gerontology: Psychological Sciences, 51, 179-188. 
http://dx.doi.org/10.1093/geronb/51B.4.P179

[53] Hammen, C.M., Brennon, P.A. and Brocque, R.L. (2011) Youth Depression and Early Childrearing: Stress Generation and Intergenerational Transmission of Depression. Journal of Consulting and Clinical Psychology, 79, 353-363. http://dx.doi.org/10.1037/a0023536

[54] Cross, W.E. (1998) Black Psychological Functioning and the Legacy of Slavery. In: Danieli, Y., Ed., International Handbook of Multigenerational Legacies of Trauma, Plenum, New York, 387-400. http://dx.doi.org/10.1007/978-1-4757-5567-1_25

[55] Zeidner, M. and Saklofske, D.H. (1996) Adaptive and Maladaptive Coping. In: Zeidner, M. and Endler, N.S., Eds., Handbook of Coping: Theory, Research and Applications, John Wiely, New York, 505-531.

[56] Jarle, E. (2003) The Course of PTSD Symptoms Following Military Training Accidents and Brief Psychological Interventions. Personality and Individual Differences, 35, 771-783. http://dx.doi.org/10.1016/S0191-8869(02)00282-9

[57] Garmezy, N. (1991) Resiliency and Vulnerability to Adverse Developmental Outcomes Associated with Poverty. American Behavioral Scientist, 34, 416-430. http://dx.doi.org/10.1177/0002764291034004003

[58] Bonanno, G.A. (2005) Resilience in the Face of Potential Trauma. Current Directions in Psychological Science, 14, 135-138. http://dx.doi.org/10.1111/j.0963-7214.2005.00347.x

[59] Ritter, C., Hobfoll, S.E., Lavin, J., Cameron, R. and Hulsizer, M. (2000) Stress, Psychological Resources and Depressive Symptomatology during Pregnancy in Low-Income, Inner-City Women. Health Psychology, 19, 576-585. http://dx.doi.org/10.1037/0278-6133.19.6.576

[60] McKenry, P. and Price, S. (2005) Families Coping with Change. In: McKenry, P. and Price, S., Eds., Families and Change: Coping with Stressful Events and Transitions, Sage Publications, Thousand Oaks, 1-24.

[61] Rotter, J.B. (1975) Some Problems and Misconceptions Related to the Construct of Internal versus External Control of Reinforcement. Journal of Consulting and Clinical Psychology, 43, 56-67. http://dx.doi.org/10.1037/h0076301 